(C) Terrie-Lynn Thompson and Catherine Adams. The definitive, peer reviewed and edited version of this article is published in Explorations in Media Ecology, 19(3), 337-349, 2020. https://doi.org/10.1386/eme_00050_7

NOTE: this is the final accepted manuscript before copy editing. There are some small changes in the final published version.

\title{
Accountabilities of Posthuman Research
}

\author{
Terrie Lynn Thompson and Catherine Adams
}

\begin{abstract}
What constitutes 'good' posthuman research? This article offers three dynamics to help assess the value of posthuman-inspired inquiry? We propose that a good posthuman research account should show evidence that the researcher: (1) attended to their own more-thanhumanness and made explicit how they interviewed and attuned to the nonhuman things of their inquiry; (2) reassembled resemblings of the posthuman world by inventively weaving and fusing human and nonhuman storylines; and (3) offered analytic insights into the liveliness of posthuman research work as the performativity of difference.
\end{abstract}

Keywords: posthuman, more-than-human, rigour, credibility, quality, posthuman accounts, qualitative research

Interest in posthuman scholarship — the inclusion of nonhumans in human and social science studies - has been rippling through the disciplines. Signalling a recognition of the importance of objects, technologies, and other thingly gatherings to the way humans think, act and dwell together in the world, this concern for the more-than-human is evidenced in the increasing number of publications, conference presentations, research proposals, as well as theory and methods courses devoted to investigating our nonhuman brethren and their complex relationships to humans. Posthuman theorizing engages a diverse collection of perspectives, each developing along rich and nuanced trajectories across multiple lines of inquiry including: Actor Network Theory (ANT) and Science and Technology Studies (STS), postphenomenology, media ecology, new materialisms, affective and non-representational theories, cosmopolitics, material anthropology, the anthropocene, naturecultures, thing power, agential realism, and objectoriented philosophy (OOP). 'Posthuman' as a term continues to be debated, discarded and reclaimed in academic circles, with some preferring the phrase 'more-than-human.' For example, Whatmore (2002, 2013: 35) advocates that 'more-than-human' more clearly points to what exceeds the human (the 'more') rather than what comes after the human (the 'post'), and as such, offers the 'more promising and pressing project'. Regardless of its unsettled moniker, the past decade has proven to be a particularly generative time for those involved in posthuman and more-than-human-inspired research endeavours. In this paper, we use both terms interchangeably.

A posthuman or more-than-human orientation insists that the researcher learns to think differently, creatively, and critically about their research: the theories upon which they draw, the process and outcomes related to the doing of research, and the involvement of researcher and the researched. The approaches employed by researchers must engage new ways to draw 'things' into their observational orbit while attempting to hold their Cartesian, anthropocentric mindset at bay. Deciding to pursue and examine the social and material relations convened between humans and nonhumans is not simply about adopting a new lexicon or learning a new methodological recipe of 'add material objects (to the account) and stir' (Mulcahy 2012: 135). The shift to 
reckon with human-nonhuman assemblages and 'coorespondences' (Ingold 2015) means the researcher situates themselves in the unmapped border territories that have traditionally separated epistemology and ontology; here dichotomies break down, blur and intertwine. As such, posthuman researchers are asked to adopt different ways of knowing and being. It can be a messy, complex, and sometimes confusing undertaking. St Pierre (2013) cautions that although new materialist epistemologies have been circulating for a while, the ontological turn is proving to be more difficult and recalcitrant. Despite the innovative strides in posthumanist theorizing and research over the last decade, much qualitative inquiry continues to be firmly rooted in anthropocentric, humanist ontologies.

One aspect of more-than-human research not well attended to thus far in the literature is how to evaluate the quality, rigour, and credibility of its research work and published accounts. In this article, we take up the question: what constitutes 'good' posthuman research? We propose that posthuman inquiry necessarily shifts the taken-for-granted ground that has previously determined what counts as 'good' qualitative research. Our intent is to consider how a posthuman account may be appropriately evaluated, including its purpose, significance and worth (Taylor 2017) as well as the multiplicity of 'goods' produced such as truth, politics, or aesthetics (Law 2004). Does the inclusion of nonhuman artefacts (objects) or more-than-human elements (things) in posthuman accounts provide meaningful contributions to understanding our everyday life and practices? In short, how can the social science research community hold posthuman accounts to account?

A longstanding concern of qualitative researchers is accounting for the rigour of their work. Challenging positivist benchmarks of validity, reliability, and generalizability, some qualitative researchers have adopted other assessment criteria such as trustworthiness, validation, authenticity, credibility, and soundness to evaluate their work. Posthuman inquiry is characterized by careful, often playful, and usually demanding conceptualizations and terminology. It makes sense that when it comes to considering the strength and quality of posthuman research, traditional conceptualizations should likewise be resisted. For example, posthumanism asks the researcher to account for their place in the world as they reconceptualize research (Ulmer 2017: 847). What is 'good' research when researchers 'perform, engage, embody, image and imagine, witness, sense, and analyse across, through, with and as, morethan-humans' (Dowling et al. 2017: 824)? Not an easy question to answer. Taylor (2017: 19-20) notes the ambitiousness of creating new knowledge-making practices:

mak[ing] space for the human alongside and with the nonhuman is a very real challenge. It requires making methodology anew with each research endeavour [...] it is about entangled responsibility and accountability. It is much easier to say you will evade the humanist legacy, than to actually do so in practice.

Attempting to articulate what makes 'good' posthuman research is a fraught endeavour from the outset. Offering a normative singular conception is not compatible with the fluid constantly decentering nature of posthuman work (or the intent of this article). Fortunately, the wave of current posthuman scholarship offers several promising insights into ways researchers are conceptualizing the integrity and quality of posthuman research work, including the accountabilities and outcomes of this research.

Below, we offer three core dynamics to help assess posthuman-inspired research accounts and hold them accountable as more-than-human inquiries. We suggest that such accounts should show evidence that the researcher sought to: (1) become attuned to their own posthumanness and make explicit how they interview or speak with things; (2) reassemble and resemble the 
posthuman world by inventively weaving and fusing human and nonhuman storylines; and (3) produce accounts that offer analytic insights into the liveliness of posthuman research work as the performativity of difference. These three dynamics are not intended as edicts but rather rules of thumb that may assist others who are drawn to undertaking more-than-human research.

\section{The blur of researcher and researched: Attuning to one's own more-than-humanness and learning to speak with things}

All posthuman accounts strive to bring materiality and the force of things out of the taken-for-granted background and into the foreground of critical inquiry. But in order to 'speak with things,' that is, inter-view an object, the researcher must first become attuned to their own more-than-humanness: who-what they themselves become with their nonhuman companions, and especially with the things of their research inquiry. Such an attunement means the researcher recognizes that "a scientist is never a "subject," alone before his "object", (Stengers 1997: 86). In such a situation, the "researcher and researched are blurred: both are potentially affectively open ... to the possibilities of particular everyday episodes' (Michael 2016: 657). Yet, 'most people ... formed within the liberal individualist tradition really understand themselves as bounded creatures who are radically separate from other lives' (Butler in Gessen 2020: n.p.). Thus a core challenge presented to the researcher is to learn how to think beyond ones selbstständig or standing-on-ones-ness, and begin to reckon with the complex ecologies of human and nonhuman intimates supporting and in relation with each of us. Dowling, Lloyd and Suchet-Pearson (2017: 827) urge that overcoming the anthropocentric bias in current research practices is "more than incorporating the "voice" of "the more-than-human" in the methodological doings" and instead opening up avenues for 'collaborating as part of more-than-human collectives' which are 'challenging human-centred author-ity.'

How does speaking and collaborating with things emerge in posthuman accounts? The creativity and agility of the researcher to be open and adapt to the object(s) of interest is critical. Adams \& Thompson (2016) suggest that objects may come to attention in multiple ways beyond initial interest in a particular technology. An object can sometimes push its way into attention. For example, Stenger (1997: 112) reports on the jouissance that can occur when an object unexpectedly intervenes between the researcher and their ideas. In this moment, an object may 'force an unexpected possibility into the exchange': a joy of not knowing (Whatmore 2003: 98). Bennett (2010: 4) describes how seeing a black glove, mat of pollen, dead rat, plastic cap, and smooth stick stuck in a grate over the storm drain

shimmied back and forth between debris and thing - between, on the one hand, stuff to

ignore $[. .$.$] and, on the other hand, stuff that commanded attention in its own right, as$ existents in excess of their association with human meanings, habits, or projects.

Bennett (2010: 4) refers to the awareness of these everyday objects as thing-power: the glove, pollen, rat, cap, and stick issue a call. And even if she did not quite understand, in the moment, what this 'thingly gathering' was saying, it nevertheless affected her. She therefore encourages posthuman researchers to 'linger in those moments during which they find themselves fascinated by objects, taking them as clues to the material vitality that they share with them' (Bennett 2010: 17).

How can such moments not affect a researcher? And how does the researcher acknowledge and explore this in their research report? We suggest that it is not merely an accounting of the things of interest in a posthuman research account that matters but accounting for how various human-nonhuman entanglements come into view, open themselves up to more 
critical questioning, and act on - and with - the researcher. The credibility of a posthuman account is reinforced when the researcher articulates how they work with thingly gatherings of interest to understand what they do. In this way, the researcher is becoming with the things of their research: they are close and entangled. Such a reflexive stance also enables the researcher to wrestle with the ethical implications and possibilities of their positioning in the research interventions they describe (Whatmore 2003: 104). McLeod (2014: 388) recounts what can happen when the researcher is open to being acted upon by other elements in research encounters: 'being affected by nonhuman elements in ways beyond my conscious control was immensely productive for the project [....] albeit problematic. I found myself living through the breakdown of a unified subject position - which was at times a painful process'.

Being able to bend and adapt traditional notions of researcher reflexivity is important in posthuman work. Reflexivity in posthuman research is less about 'inner mental activities' and more about thinking through a transcorporeal process of engagement (Taguchi 2012: 267). Michael (2016: 650) writes that in the enactment of research events, nonhuman and human elements affect one another 'in ways that unsettle the very "meaning" of that event'. Writing posthuman accounts demands agility to create and navigate multiple realities and grapple with uncertainties, gaps, perplexities, and the ever-present unknown.

In assessing a posthuman account the reader may wish to ascertain the transparency of the researcher's reflexivity. Does the researcher acknowledge how they were implicated and affected by the materiality of the research project? Groten's (2020 this issue) interview of the music sample illustrates such posthuman reflexivity as he describes how he becomes the 'sampling-human' with his Zoom H4N (digital audio recorder), and responding to the invitational qualities of everyday things as they become co-authors of music. He adds: 'In following the actors, I enjoyed the insight into the sampling composer as a hybridic entity, who not only requires a change in attitude, but who arises from the hyphenated space between person and thing - between human and digital recorder.' Groten's reflexivity is accompanied by strong engagement in possibilities and openness to the 'not yet.' Posthuman work means the researcher does not position themselves as the all-seeing knower (Michael 2016: 653). Instead such inquiry rethinks one's understandings of the affordances between bodies and objects in more speculative and provisional ways: learning to be affected by the objects at hand, challenging conventional interpretations, and hinting at possibilities that everyday events offer rather than providing definitive accounts (Michael 2016).

A second example describes the process and accounting of how human actors become with objects. In Woodward et al. (2015: 508) a 'technical object actively introduces its own problematic field, the experts are swept up as participants in its resolution, just as the technical object ... brings with it some of the human in its constitution.' It begins with a problem about how the diameter of Hurricane Katrina was being represented in the 3D animation software. Drawing on Simondon's work, this posthuman account highlights how researchers should not ignore but instead engage intensely with the messy and 'productive roles of the object, as these jointly unfold during the complex shuffles of production' of sophisticated visualizations (508). Throughout this fine-grained analysis, readers glimpse the role that technical objects play as they pose problems in need of solutions, and dragging 'team members past their territories of expertise and into a more complicated relation of collective production with the technical object' (506). Throughout this process, Woodward et al. (2015: 503) work to 'flatten' ontological relations in order to broaden their focus beyond the human actors to the more 'subtle, transindividual relations produced across the asymmetrical workings of technical objects and 
humans'.

\section{Posthuman fabrications: Weaving human and nonhuman storylines}

As the articles in this special issue amply demonstrate, there are different ways to weave human and nonhuman storylines together in an effort to describe the unique intricacies and complex tensions of human-nonhuman relations. While the ethos of posthuman research necessarily involves a degree of de-centering the human — while not de-humanizing the inquiry, how a researcher negotiates the balance of their human/nonhuman attention and presence also depends on the underlying theoretical framings they subscribe to. For example, postphenomenologists and media ecologists tend to put a thumb on the human or 'subjective' side of the scale, whereas ANT theorists usually press down on the 'objective', nonhuman side. Regardless, posthuman research recognizes that all such binaries (subjective/objective, human/nonhumans) are themselves fictions - albeit powerful — that must be questioned and sometimes held at bay in order to arrive at more robust and inclusive understandings of our larger human/nonhuman relational networks and more-than-human environments.

Along these lines, we consider one heuristic_- 'Gathering Anecdotes' (Adams and Thompson 2016) indispensable to posthuman inquiry because of its capacity to help us 'think the human and the technological in a single breath' (Adams 2017: 230). Posthuman anecdotes offer an accounting and appreciation of the activities of an object (or objects) of interest in everyday life. However, in their construction, anecdotes also serve to attune the researcher, and ultimately the reader, to what things $d o$. Anecdotes sometimes require inventive fabricating as they single out both human and nonhuman storylines, then interweave, and at times, fuse these storylines together.

A practical and perplexing question here is how a researcher develops and presents these anecdotes. One consideration is the symmetry of the anecdotes when reading throughout an account: Are humans the only (or main) narrators? How do objects appear in these anecdotes and in what ways? Some resesarchers may be tempted, in an effort to override their humanist tendencies, to highlight the nonhumans while eliding the human contributions. This is a mistake. It is always the entanglements, intersections, intra-actions - the 'both together' - that must be kept in focus, not the who or the what but the who-what.

Elsewhere, we describe anecdotes as 'reassembled resemblings in the enactment of research practice' (Adams and Thompson 2016: 31). At first glance, the purpose of anecdotes appears to be descriptive, a storied retelling about humans interacting with things within the context of everyday practice. As textual entities they are indeed this. But they are more. Specifically, anecdotes $d o$. They themselves are performative (not static) assemblages: textual 'recreations that reassemble, resemble, resonate, move, animate, and unfold' (Adams \& Thompson 2016: 31).

In posthuman accounts, the reader may discover that the researcher has carefully delineated the anecdotes in the text. For example, Gross (2020 this issue) gives key anecdotes themed subtitles, and her anecdotal text is indented and italicized. Turville (2017) adopts a similar approach to separating her key anecdotal material from her analytic reflections on them. Other posthuman studies, like Latour's (1992) 'Where are the missing masses? The sociology of a few mundane artifacts,' may open with a key anecdote. This technique is repeated by Groten (2020 this issue) and Ireland (2020 this issue). Opening with a strong, posthuman anecdote can be especially effective in orienting the reader to the researcher's intent to foreground the nonhuman and it's taken-for-granted entanglements and meaningful contributions to human 
practice. Such a beginning also sets in motion a more-than-human perspective, where the participation and co-agential performance of things is made evident.

At other times, it can be difficult to tell where an anecdote begins and ends. For example, Guest (2020 this issue) describes tweets, Twitter, software such as TAGS and Treeverse, websites, outputs of invisible algorithms, and moments of professional learning by teachers. Human and nonhuman storylines are at times singular and particular, at other times, deliberately interwoven and fused in messy swirl of actions and online happenings in which the human actors and technologies of interest cannot be separated. Screen captures may be used to help make the often ephemeral digital actors and intra-actions more concrete. In some posthuman accounts, one anecdote may flow into another without neat and tidy demarcations in the spirit of the flâneur. Similar to Taylor and Gannon (2018: 468), Guest (2020 this issue) 'mess[es] with images and text to keep meaning on the move'. Anecdotes may be written in first person (e.g., Groten; Gross), second person (e.g., Ireland's opening anecdote), or third person (e.g., Ireland; Guest). They may be constructed as recollections (e.g., Groten; Gross); observations of self or others (e.g., Lemermeyer 2020 this issue; Groten; Gross; Guest) or recorded and then transcribed as play-like dialogues (e.g., Ireland).

In Adams and Thompson (2016: 19) we drew on Michael's (2004: 20) argument that entities (objects) should not be "spoken "about", "for", or "of". Instead the researcher 'speaks "with", "by", "through", and "as" these entities'. However, if one takes 'interviewing objects' (Adams \& Thompson 2016) too literally, the researcher can run into another potentially dangerous terrain: anthropomorphizing objects. This is not the intent of a posthuman anecdote. Including direct quotes from human participants makes sense, as does, for example, including the utterances of Alexa or Siri. However, for the most part, the speaking of things is silent. Too, it is important to question and interrupt the standard practice of assuming qualitative research accounts are more credible and trustworthy because they foreground the voice of human participants in the form of direct quotes. The credibility of a posthuman account is rooted in its ability to reassemble and resemble the everyday intra-actions between both humans and nonhumans, mast of which transpire in silence, often in the background of human attention.

Accounting for such intra-actions presents a key challenge facing researchers constructing anecdotes. Taylor (2017: 4) outlines five key foci of current posthuman scholarship, one of which suggests that strong posthuman accounts are characterized by attention to practices 'in all its messiness' rather than an 'interest in epistemological correspondence'. Posthuman anecdotes in particular attempt to describe the fluid and elusive nature of human-nonhuman relations and enactments of practices. This is a resolute but often evanescent effort, marked by stubborn and elusive presences and absences. As Law (2004: 2) observes, 'simple clear descriptions don't work if what they are describing is not itself very coherent'. Or to put it another way, it is important to 'recognize the limits of human-centred methodologies and acknowledge the sometimes unknowable (from a human perspective) worlds of ants and worms' (Dowling et al. 2017: 826).

Such reassembled resemblings in text demand that the impartial 'view from nowhere' is relinquished and humbly replaced by a partial, up-close-and-personal view in the midst of things: situated, embodied and unfolding. Vannini (2015: 15) suggests that this sort of nonrepresentational research should aim to 'enliven rather than report, to render rather than represent, to resonate rather than validate, to rupture and re-imagine rather than to faithfully describe, to generate possibilities of encounter rather than construct representative ideal types'. Anecdotes - and the process of anecdoting - is an exercise in modesty and humility. Such an 
orientation is consistent with Law's (2004: 3) assertion that methodological assemblages - which could include anecdotes - rely on techniques of 'deliberate imprecision' to make knowing possible; a way of 'knowing the indistinct and the slippery without trying to grasp and hold them tight'.

Finally, although the challenge is to let the things of the world speak for themselves, it is important to recognize the limits of our situated understandings (Adams and Thompson 2016). Events and processes are complex 'because they necessarily exceed our capacity to know them' (Law 2004: 6). Strong posthuman accounts offer inventive writing that help to make 'matter intelligible in new ways and to imagine other possible realities presented in the data: a real beyond those produced by processes of recognition and identification ... in discursive positionings' (Taguchi 2012: 267 emphasis in original). This may becomes more achievable when the focus is 'not on things already made but on things in the making' (St. Pierre 2018: 604). Exhibiting a respect for, and a commitment to, articulating the vibrancy, animation, and provisional nature of human-nonhuman practices may be another way to evaluate the quality of a posthuman account.

\section{Lively accounts and the performativity of difference}

Some posthuman accounts explain that they draw on more-than-human theorizing and methodologies in order to ask different questions. Mol (2010: 262) summarizes these aspirations with respect to ANT:

The strength of ANT is not in its coherence and predictability, but in what at first sight, or in the eyes of those who like their theories to be firm, might seem to be its weakness: its adaptability and sensitivity. If ANT is a theory, then a theory to help tell cases, draw contrasts, articulate silent layers, turn questions upside down, focus on the unexpected, add to one's sensitivities, propose new terms, and shift stories from one context to another.

While this goal may be germane to research more broadly it is especially relevant in posthumanist work. A posthuman research text should demonstrate its liveliness, that is, how the research itself - and the story of the research - enacted, enacts, or will enact difference. Does this posthuman account change ones way of thinking or knowing? In what ways has the researcher, in Latour's (2004: 205) words, 'learn[ed] to be affected' that is, 'effectuated, moved, put into motion by other entities'? Being receptive to the possibilities that tangling and becoming entangled with thingly gatherings offer, it is not uncommon for a researcher to re-formulate their research question as their work progresses. Influenced by Stengers work, Whatmore (2003: 103) advocates the importance of 'keeping questions open though the research process' by insisting on the "produced-ness of "data" and the creative and sometimes contrary possibilities generated in and by exchanges between the researcher and researched'.

Ongoing questioning is a necessity in researching phenomena and practices that are unknowable in advance. Methods must remain open throughout data collection and analysis, as the researcher struggles to articulate the dynamics of fleeting and stable human-objects relations and relating. In this respect, the performativity of a posthuman account may be akin to Rose's (2003: 63) observation of how Irigaray's work is characterized by questions that makes the reader think with her: 'her [Irigaray] writing and I are doing something together at the edge of what is presently understood'. Working at the edge between the known and unknown recalls a key motive behind posthuman inquiry: to try to 'think the human and the technological in a 
single breath.' Such work can itself be a lively material-semiotic actor: the writer, reader, and text pulling at, through, and between each other.

Strong posthuman accounts have the potential to enact different politics, novel sociomaterial arrangements and thus new realities. Bennett (2010: viii) asks: 'How would political responses to public problems change were we to take seriously the vitality of (nonhuman) bodies?' Law (2004: 141) writes that sociomaterial work confronts us 'with a quite different set of important puzzles about the nature of the real and how to intervene in it'. This includes attending to the ethical implications and responsibilities towards the presences, absences, and sustainability of things. Paulson (2001: 112), influenced by Stengers' work on cosmopolitics, states that it is 'not enough to decide to include nonhumans in collectives [....] The crucial point is to learn how new types of encounter (and conviviality) with nonhumans [... can give rise to new modes of relations with humans, i.e., to new political practices'.

One example of the performativity of difference is Ireland's (2020 this issue) interview of SimMan, which enables her to address thorny issues about patient-centered care and the allocation and effectiveness of simulation technologies for medical education. Her ANT-based analysis highlights how objects and practices assemble, mediate, and connect multiple worlds of the real, pretend, and actual to bring different but partially connected sociomaterial realities into being. Her research elides a straightforward yes-no response to whether or not these simulation technologies 'work' and instead highlights the complexity, the continual doings (an un-doings) of things and people that make them work every day, and the sometimes contradictory and uncanny nature of these arrangements. The account moves beyond mere discussion of the 'fidelity' of the human body in simulation education and instead attempts to draw attention to the importance of the imaginary in these complex practices. 'By demonstrating how humans might think with other species, phenomenon, and elements' (Ulmer 2017: 838), Ireland's account offers hope that humans implicated in medical education can 'begin to think differently about themselves' especially in relation to simulation technologies.

\section{Accounts and Accountabilities}

In this article, we considered how posthuman theorizing and methodologies have shifted conceptions of what makes for good research and therefore better understand the implications for assessing the purpose and significance of posthuman accounts. Drawing on literature and research experiences, we set out to describe three dynamics which could serve as an initial lens for holding posthuman research work accountable: (1) explain how the researcher speaks with things; (2) actively engage in weaving and fusing of human and nonhuman storylines; and (3) acknowledge the liveliness of posthuman research work in the performativity of difference. This article attempts to keep methodology on the move. It is not meant to offer a definitive checklist of what constitutes a good posthumanist account. In our own work, and especially our work with doctoral students who chose to follow a materialist posthuman orientation, we see these as relevant and timely questions. We hope that the ideas in this paper can serve as springboards to continue discussing the accounts of posthuman-oriented research and what makes them strong, worthy, and credible.

There is no easy methodological prescription for scholars interested in doing more-thanhuman inquiry. Lather (2006: 52) observes that doing research at this historical juncture vexed by concerns of authority and legitimization — a 'time between the no longer and the not yet' - the task is to produce different knowledge differently. We are well into the midst of challenging the 'humanist mastery of the coding and thematizing practices on which the presumed analytical 
rigour and validity of data analysis procedures are said to depend' (Taylor 2017: 19). It is a less than comfortable space, but it is full of rich and innovative potential. Describing nonrepresentational research, Ingold (2015: vii) hints at such new possibilities, which seems applicable to what it means to do posthuman research that is valued and valuable and how the accounts of such research might be assessed:

It is not a regulated set of steps to be taken towards the realization of some predetermined end. [...] It is a correspondence, in the sense of not coming up with some exact match or simulacrum for what we find in the things and happenings going on around us, but of answering them with interventions, questions, and responses of our own.

St Pierre (2018: 604) argues that such shifts cannot be accomplished within 'methodological enclosure': this work is 'experimental [...] risky, creative, surprising, and remarkable'. More-than-human researchers will find their way in this space. Some, such as Shadler (2019: 215-16), acknowledge that it may entail small steps: 'When I started to work with new materialisms in the field of family studies, I knew it would not be possible to completely break the boundaries of analytical writing styles, but that it might be possible to bend them'. Law (2004: 154) reminds that in contrast to the 'dominant truth-related methods that expect definite results and so enact definite realities', new more-than-human methods 'should sometimes, perhaps often, manifest realities that are indefinite' and sometimes non-coherent, but that this is 'not necessarily signs of methodological failure'. Alongside the innovative and creativity of new methods, openness to the possibilities of the future, and a 'disorderly will to experiment and to fail' (Vannini 2015: 324) accounting for the value and strength of posthuman accounts is a worthy challenge.

\section{References}

Adams, Catherine (2017), 'Technology's hidden curriculum and the new digital pharmakon', in j. jagodzinski (ed), The Precarious Future of Education: Risk and Uncertainty in Ecology, Curriculum, Learning, and Technology, London: Palgrave MacMillan, 225-240.

Adams, Catherine, and Thompson, Terrie Lynn (2016), Researching a Posthuman World: Interviews with Digital Objects, London: Palgrave Macmillan.

Bennett, Jane (2010), Vibrant Matter: A Political Ecology of Things, Durham, NC: Duke University Press.

Dowling, Robin, Lloyd, Kate and Suchet-Pearson, Sandra (2017) 'Qualitative methods II: 'More-than-human' methodologies and/in praxis', Progress in Human Geography, 41:6, pp. 823-831, DOI: 10.1177/0309132516664439

Gessen, Masha (2020, February 9), 'Judith Butler wants us to reshape our rage,' The New Yorker, https://www.newyorker.com/culture/the-new-yorker-interview/judith-butler-wants-us-toreshape-our-rage

Ingold, Tim (2015), 'Foreword', in P. Vannini (ed.), Non-Representational Methodologies: Re- 
envisioning Research, London: Routledge, pp. vii-x.

Latour, Bruno (1992) 'Where are the missing masses? A sociology of a few mundane Artifacts,' in W.E. Bijker and J. Law (eds), Shaping Technology/Building Society:

Studies in Sociotechnical Change, Cambridge, MA: TheMIT Press, 225-258.

Latour, Bruno (2004) 'How to talk about the body? The normative dimension of science studies', Body \& Society, 10:2-3, 205-229, DOI: 10.1177/1357034X04042943

Law, John (2004), After Method: Mess in Social Science Research, Abingdon, UK: Routledge.

McLeod, Kim (2014) 'Orientating to assembling: Qualitative inquiry for more-than-human worlds,' International Journal of Qualitative Methods, 13, 377-394.

Michael, Mike (2016), 'Notes toward a speculative methodology of everyday life', Qualitative Research, 16:6, 646-660, DOI: 10.1177/1468794115626245

Mol, Annemarie (2010) 'Actor-Network Theory: Sensitive terms and enduring tensions, Kölner Zeitschrift für Soziologie and Sozialpsychologie, 50:1, 253-269. Retrieved from http://hdl.handle.net/11245/1.330874

Mulcahy, Diane (2012) 'Thinking teacher professional learning performatively: A socio-material account', Journal of Education and Work, 25:1, 121-139, DOI:10.1080/13639080.2012.644910

Rose, Gillian (2003) 'A body of questions', in M. Pryke, G. Rose, and S. Whatmore (eds), Using Social Theory: Thinking through Research, London: Sage, 47-64.

Schadler, Cornelia (2019) 'Enactments of a new materialist ethnography: Methodological framework and research processes', Qualitative Research, 19:2, 215-230, DOI:

$10.1177 / 1468794117748877$

St. Pierre Elizabeth Adams (2013) 'The posts continue: Becoming', International Journal of Qualitative Studies in Education, 26:6, 646-657, DOI: 10.1080/09518398.2013.788754

St. Pierre, Elizabeth Adams (2018) 'Writing post qualitative inquiry, Qualitative Inquiry, 24:9, 603-608.

Stengers, Isabelle (1997). Power and Invention: Situating Science (trans. P. Bains), Minneapolis, MN: University of Minnesota Press.

Taguchi, Hillevi Lenz (2012) 'A diffractive and Deleuzian approach to analysing interview data', Feminist Theory, 13:3, 265-281, DOI: 10.1177/1464700112456001

Taylor, Carol (2017) 'Rethinking the empirical in higher education: Post-qualitative inquiry as a less comfortable social science', International Journal of Research \& Method in Education, 
$40: 3,311-324$.

Taylor, Carol A. and Gannon, Susanne (2018) 'Doing time and motion diffractively: Academic life everywhere and all the time', International Journal of Qualitative Studies in Education, 31:6, 465-486, DOI: 10.1080/09518398.2017.1422286

Turville, Joni (2017), 'If e-mail could speak, what would it say? Interviewing objects in a digital world,' Explorations in Media Ecology 16:2-3, pp. 157-173.

Ulmer, Jasmine B. (2017) 'Posthumanism as research methodology: Inquiry in the Anthropocene', International Journal of Qualitative Studies in Education, 30:9, pp. 832-848, DOI:

10.1080/09518398.2017.1336806

Vannini, Phillip (2015), Non-Representational Methodologies: Re-envisioning Research. New York: Routledge.

Woodward, Keith, Jones III, John Paul, Vigdor, Linda, Marston, Sallie A., Hawkins, Harriet and Dixon Deborah P. (2015) 'One sinister hurricane: Simondon and collaborative visualization', Annals of the Association of American Geographers, 105:3, 496-511.

Whatmore, Sarah (2002), Hybrid Geographies: Natures Cultures Spaces, London: Sage.

Whatmore, Sarah (2003), 'Generating materials', in M. Pryke, G. Rose, and S. Whatmore (eds), Using Social Theory: Thinking through Research, London: Sage, 89-104.

Whatmore, Sarah (2013) 'Earthly powers and affective environments: An ontological politics of flood risk, Theory, Culture \& Society, 30: 7/8, 33-50, DOI: 10.1177/0263276413480949 